\title{
Interannual variability of wind power input to near-inertial motions in the North Atlantic
}

\author{
Tina Dippe ${ }^{1} \cdot$ Xiaoming Zhai ${ }^{2} \cdot$ Richard J. Greatbatch $^{1} \cdot$ Willi Rath ${ }^{1}$
}

Received: 21 November 2014 / Accepted: 24 March 2015 / Published online: 10 April 2015

(C) Springer-Verlag Berlin Heidelberg 2015

\begin{abstract}
Near-inertial oscillations are ubiquitous in the ocean and are believed to play an important role in the global climate system. Studies on wind power input to near-inertial motions (WPI) have so far focused primarily on estimating the time-mean WPI, with little attention being paid to its temporal variability. In this study, a combination of atmospheric reanalysis products, a high-resolution ocean model and linear regression models are used to investigate for the first time the relationship between interannual variability of WPI in the North Atlantic and the North Atlantic Oscillation (NAO), motivated by the idea that the NAO serves as a good indicator for storminess over the North Atlantic and that storms account for the majority of WPI. It is found that WPI at low and high latitudes of the North Atlantic is significantly correlated to the NAO, owing to its influence on the configuration of the storm track. Positive (negative) NAO conditions are associated with increased WPI in the subpolar (subtropical) ocean. Basin-wide WPI is found to be significantly enhanced under negative NAO conditions, but is not significantly different from the climatological average under positive NAO conditions. This indicates a weak inverse relationship between basin-wide WPI and the NAO, contradicting intuitive
\end{abstract}

Responsible Editor: Chris Wilson

This article is part of the Topical Collection on Atmosphere and Ocean Dynamics: A Scientific Workshop to Celebrate Professor Dr. Richard Greatbatch's 60th Birthday, Liverpool, UK, 10-11 April 2014

Tina Dippe

tdippe@geomar.de

1 GEOMAR | Helmholtz Centre for Ocean Research Kiel, Kiel, Germany

2 Centre for Ocean and Atmospheric Sciences, School of Environmental Sciences, University of East Anglia, Norwich, UK expectations. The asymmetric impact of the NAO on basinwide WPI results from greater sensitivity of WPI to nearinertial wind forcing at lower latitudes due to the variation of the Coriolis parameter with latitude.

Keywords Near-inertial currents · North Atlantic Oscillation · Wind power input · Interannual variability · Ocean modelling · Statistical modelling

\section{Introduction}

Near-inertial oscillations are ubiquitous in the ocean and are believed to play an important role in the global climate system by acting as an energy source for maintaining diapycnal mixing in both the upper and deep ocean. Recent high-resolution modelling studies (e.g. Furuichi et al. 2008; Zhai et al. 2009) suggest that the majority (75-85\%) of wind energy input to near-inertial motions is dissipated within the top $200 \mathrm{~m}$ of the water column owing to enhanced shear at the base of the surface mixed layer, causing a deepening of the mixed layer and cooling of the sea surface temperature (SST). These SST changes-especially those in the Tropics-have been found to be potentially capable of influencing the entire climate system via atmospheric teleconnections (Jochum et al. 2013). The rest (15$25 \%$ ) of the wind-induced near-inertial energy (NIE) propagates into the interior of the ocean in the form of nearinertial waves via either the beta-dispersion effect (e.g. Anderson and Gill 1979; Gill 1984) or the 'chimney effect', i.e. trapping and downward propagation of near-inertial waves in anticyclonic eddies (e.g. Kunze 1985; Lee and Niiler 1998; Zhai et al. 2005, 2007). In the deep ocean, breaking of these waves generates mixing that in turn contributes to maintaining the global Meridional Overturning 
Circulation (MOC) against stable stratification (Munk and Wunsch 1998).

A number of studies estimated wind power input to nearinertial motions in the ocean (WPI; e.g. Watanabe and Hibiya 2002; Alford 2003; Furuichi et al. 2008). Accurate estimates of WPI require high temporal (less than a few hours) and spatial resolution of both surface wind stress and surface near-inertial currents (Jiang et al. 2005; Rimac et al. 2013). However, since such high-resolution global datasets-particularly the dataset of near-inertial currents - are generally not available, most investigations of WPI so far have employed the slab model proposed by Pollard and Millard (1970). The slab model is appealing because it enables estimates of WPI and NIE using only the wind stress, prescribed mixed layer depth and an empirical damping coefficient. For example, Watanabe and Hibiya (2002) used the slab model to estimate the global time-mean WPI and found a rate of about $0.7 \mathrm{TW}$ $\left(1 \mathrm{TW}=10^{12} \mathrm{~W}\right)$, which was later updated by Alford (2003) to $0.47 \mathrm{TW}$. Although the slab model proves to be qualitatively useful, comparisons with field observations (Plueddemann and Farrar 2006; Guan et al. 2014) have highlighted the fact that due to the lack of a dissipation mechanism operating on short time scales, ${ }^{1}$ the slab model can systematically overestimate the energy flux from the wind to surface near-inertial currents, especially during strong wind events. Recently, Rimac et al. (2013) investigated the influence of different temporal and spatial resolutions of the wind stress field on WPI using a global eddy-permitting ocean model and found that global WPI can reach values as high as $1.1 \mathrm{TW}$ given sufficient high-resolution wind forcing.

So far, studies on WPI have focused primarily on estimating the time-mean WPI using either the slab model or more sophisticated ocean general circulation models, with little attention being paid to the temporal variability of WPI and NIE, although synoptic storms, responsible for the majority of the WPI (D'Asaro 1985), are known to vary significantly from 1 year to another in both their strength and spatial distribution.

Storm activity over the North Atlantic is closely linked to the North Atlantic Oscillation (NAO) (e.g. Hurrell 1995; Greatbatch 2000; Hurrell et al. 2003). Figure 1 shows Hurrell's station-based NAO index (Hurrell 1995) for the period considered in this study, i.e. 1980 to 2013. In general, positive phases of the NAO are accompanied by mild and wet conditions in Western Europe and cold, dry conditions in north-eastern North America and Greenland. Negative NAO conditions reverse this pattern. The mechanism steering these changes is connected to the variability of the North Atlantic storm track: Positive NAO years tend to produce more intense and more frequent storms with the storm track running into the Norwegian Sea. During negative NAO years, storms

\footnotetext{
${ }^{1}$ Such as mixed-layer deepening due to entrainment as proposed for example by Furuichi et al. (2008) and Zhai et al. (2009).
}

occur less frequently and are of reduced intensity, and the storm track becomes more zonally oriented, allowing more storms to enter the Mediterranean basin (Lau 1988; Rogers 1997). However, the influence of these changes of storm activity on WPI to near-inertial motions is yet to be explored.

In this study, we investigate for the first time the relationship between the interannual variability of wind power input to near-inertial motions in the North Atlantic and the NAO, motivated by the ideas that the NAO serves as a good indicator for storm activities over the North Atlantic and that storms account for the majority of WPI. We begin in Section 2 by describing the atmospheric datasets and ocean model used for this study. Section 3 investigates the variability of near-inertial wind stress associated with the NAO and its relationship to the storm track. Results of a high-resolution ocean model driven by wind forcing under positive and negative conditions are presented and discussed in Section 4. In Section 5, we identify a useful atmospheric proxy for WPI and use it to estimate the interannual variability of WPI to the North Atlantic. A summary and discussion of the findings is provided in Section 6 .

\section{Model and methods}

\subsection{Near-inertial quantities}

To obtain near-inertial quantities, we apply a 9th-order Butterworth band-pass filter to the datasets. The nearinertial band is centred at the local inertial frequency $(=2 \Omega \sin (\varphi)$, where $\varphi$ is the latitude), with upper and lower thresholds of the band given by the inertial frequency at latitude $\varphi \pm 10^{\circ}$ and $\varphi \pm 1^{\circ}$ for ocean currents and wind stress data, respectively. The broader nearinertial band for ocean currents is justified, since the inertial peak in ocean current data is very pronounced, whilst, in contrast, wind variability displays no clear near-inertial peak (e.g. Thomson 1983).

The near-inertial wind stress magnitude (NIWSM) is then defined as the magnitude associated with near-inertial components of wind stress. NIWSM is available for each time step of the filtered time series. Mean NIWSM is the average of the NIWSM-time series at a given location. To be able to carry out comparisons with the study by Rath et al. (2014), we define the near-inertial wind stress variance (NIWSV) as

$\mathrm{NIWSV}=\tau_{x, \mathrm{I}}^{2}+\tau_{y, \mathrm{I}}^{2}=\mathrm{NIWSM}^{2}$,

where $\tau_{x, \mathrm{I}}$ and $\tau_{y, \mathrm{I}}$ are the band-pass-filtered-i.e. near-inertial - components of the surface wind stress. Mean NIWSV is defined analogously to mean NIWSM. 


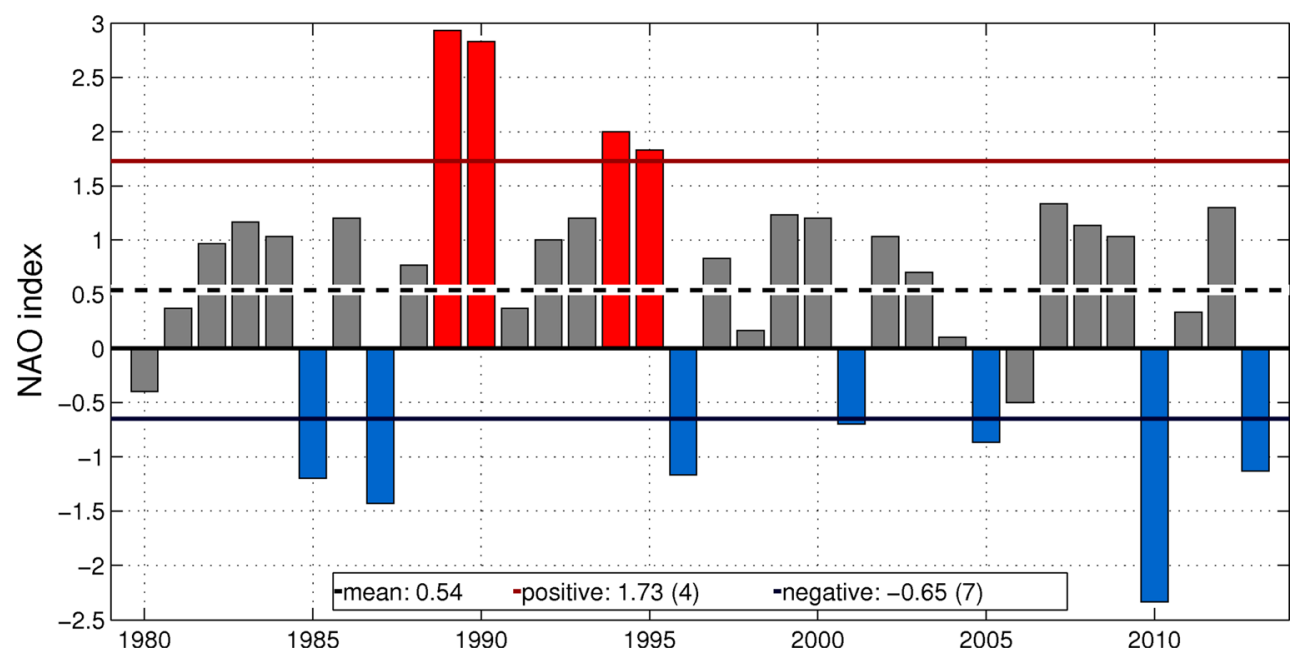

Fig. 1 Hurrell's station-based winter (JFM) NAO index for the time span considered in this study (1980 to 2013). Red (blue) bars denote the years that were used for composites of positive (negative) NAO conditions throughout this study. The dashed line shows the average NAO index

WPI is calculated as

$W P I=\vec{\tau} \cdot \vec{u}_{\mathrm{I}}$,

where $\tau$ is unfiltered wind stress, and $\mathbf{u}_{\mathrm{I}}=\left(u_{\mathrm{I}}, v_{\mathrm{I}}\right)$ is the nearinertial band-pass filtered surface ocean velocity.

\subsection{Atmospheric datasets and storm track measures}

To investigate the atmospheric conditions associated with different NAO phases, we use the 6-hourly surface wind stress and sea level pressure (SLP) data provided by the National Centers for Environmental Prediction/National Center for Atmospheric Research (NCEP/NCAR) reanalysis product (Kalnay et al. 1996). The wind stress is provided on a Gaussian T62 grid and the SLP on a $2.5^{\circ}$ longitude $\times 2.5^{\circ}$ latitude grid, respectively. Due to insufficient data coverage north of $70^{\circ} \mathrm{N}$, we restrict our analysis of atmospheric data to the North Atlantic domain between $20^{\circ}$ and $65^{\circ} \mathrm{N}$. Note, however, that even at $65^{\circ} \mathrm{N}$, near-inertial processes will be poorly resolved in a 6-hourly dataset. For a more thorough discussion, refer to Section 6.

Storm tracks are diagnosed in two ways. An average quantity is obtained by band-pass filtering SLP in the synoptic band of 2-6 days and calculating its variance during the months January-February-March (JFM). This corresponds to the standard definition of a storm track (Wallace and Gutzler 1981; Blackmon et al. 1984a, b; Wallace et al. 1988) and is referred to as the storm track throughout this study. In addition, actual storm path data are used to get an impression of what the individual winter storms looked like in selected years. The storm path data are provided by Sergey Gulev and Natalia Tilinina at the P. P. Shirshov Institute of Oceanology of the Russian Academy of Sciences, who used the NCEP/NCAR dataset to for the considered time span (0.54). Composite averages are 2.40 and -1.26 for positive and negative conditions, respectively. Solid lines denote the mean of the time series \pm 1 standard deviation (compositing condition)

diagnose the tracks of individual storm centres for the northern hemisphere by applying a semi-manual tracking algorithm (Gulev et al. 2001). To avoid confusion, individual storm centre tracks are referred to as storm paths.

In Section 3.3, we present the surface wind stress power spectral density in the North Atlantic for 1980 to 2013 as a function of latitude. The spectra were obtained as follows: We first calculated the spectra of the zonal and meridional wind stress components separately for each winter (JFM) from 1980 to 2013 and subsequently summed up the squared spectral values of the horizontal wind stress components to yield a consistent estimate of wind stress power spectral density following Rath et al. (2014). Subsequent zonal averaging was employed for smoothing.

For the NAO, we use the traditional station-based index (Hurrell 1995). As noted by Hurrell et al. (2003) for the winter season, there is very little difference between this index and an index based on an EOF analysis. The NAO index used here is obtained from the Climate Analysis Section of the National Centre for Atmospheric Research (Hurrell 1995). It is shown in Fig. 1. NAO composites are used to assess 'typical' conditions in positive or negative NAO years. Single years are included in the composite, if the NAO index of that year departs from the mean NAO index by more than 1 standard deviation, based on the time span 1980 to 2013. Years contributing to the composite for positive (negative) NAO conditions are marked red (blue) in Fig. 1.

\subsection{Ocean model}

The ocean model used in this study is a North Atlantic configuration of the MIT General Circulation Model (Marshall et al. 1997). The model domain spans from $14^{\circ} \mathrm{S}$ to $74^{\circ} \mathrm{N}$ and from 
$100^{\circ} \mathrm{W}$ to $20^{\circ} \mathrm{E}$, with a horizontal resolution of $1 / 10^{\circ}$. There are 33 geopotential levels whose thickness increases with depth, ranging from $10 \mathrm{~m}$ at the surface to $250 \mathrm{~m}$ at the ocean bottom. The K-profile parameterization (KPP) mixing scheme (Large et al. 1994) is used in the vertical direction and biharmonic mixing is used in the horizontal. Readers are referred to Zhai and Marshall (2013) for further details.

The model was first spun up for 23 years at $1 / 5^{\circ}$ resolution and then further spun up for another 30 years at $1 / 10^{\circ}$ resolution, both driven by the NCEP/NCAR climatological monthly mean forcing. After the spin-up, two additional model runs were conducted at $1 / 10^{\circ}$ resolution using the 6-hourly wind stress forcing in the winters of 1989 and 2010 (JFM), respectively. The reason for choosing 1989 and 2010 is that the NAO index for these 2 years was exceptional: the NAO index in 1989 (2010) is the most positive (negative) since the advent of satellite observations (values are 2.93 and -2.33 , respectively). The model variables were saved every $2.5 \mathrm{~h}$.

\section{Dependence of atmospheric conditions on NAO}

\subsection{Storm track}

Figure 2 shows the climatological storm track as well as storm track composites under positive and negative NAO conditions

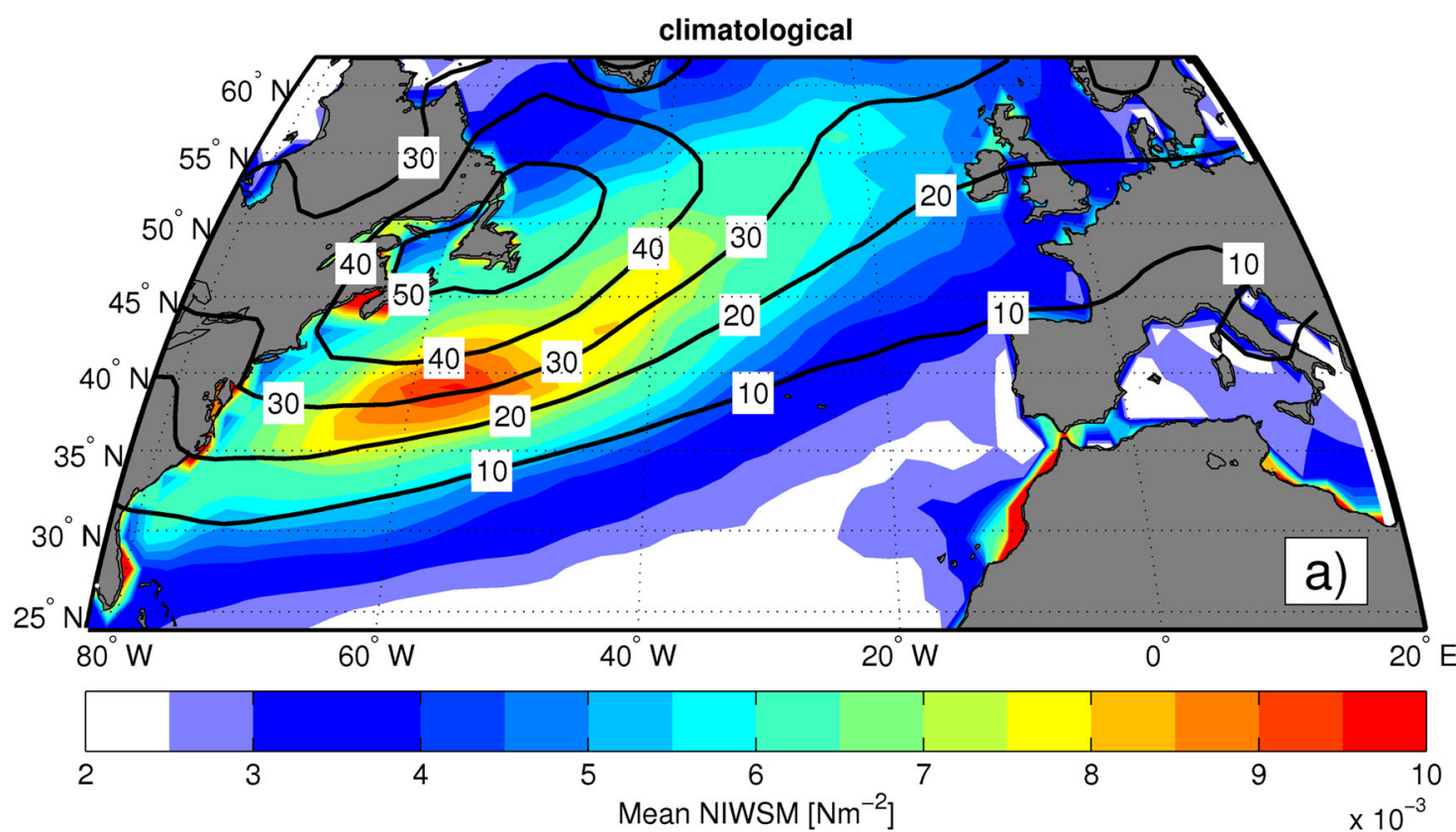

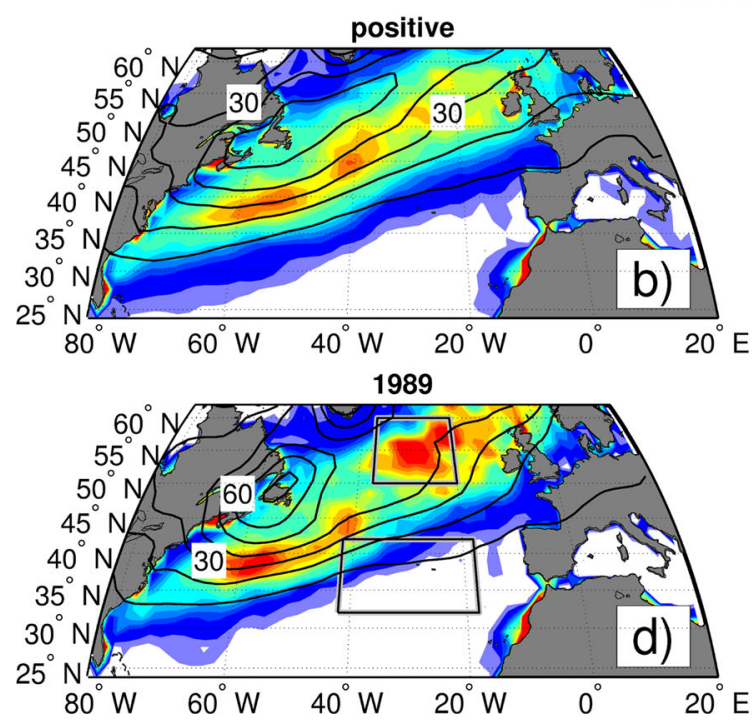

Fig. 2 Mean NIWSM $\left[\mathrm{N} \mathrm{m}^{-2}\right]$ in JFM (shading) and storm track (black contours). a Climatology (1980 to 2013), b composite for positive NAO phase (cf. Fig. 1), c composite for negative NAO phase, d 1989 and e

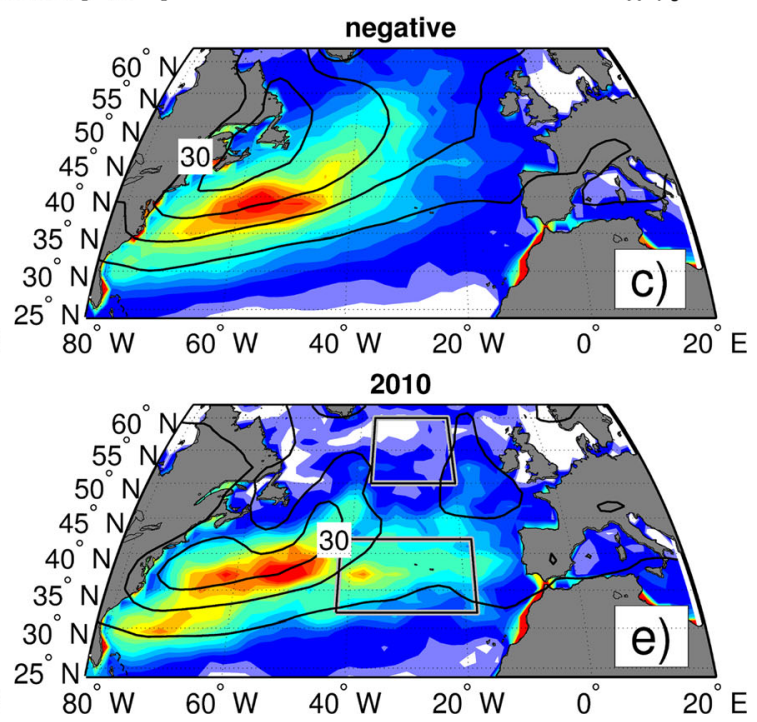

2010. Shading is equal in all panels. The storm track contour interval is $10 \mathrm{hPa}^{2}$. Black boxes denote the region of enhanced WPI in the subpolar (subtropical) North Atlantic in 1989 (2010), cf. Fig. 5 
(black contours). Consistent with previous studies (e.g. Rogers 1997), the climatological storm track is centred over Newfoundland and stretches north-eastward towards Iceland. The most significant impact of the NAO appears to be on the tail of the storm track, shifting it slightly into the subtropics under negative NAO conditions and pulling it into the Nordic Seas under positive NAO conditions.

To illustrate the specific storm track configurations in the winters of 1989 and 2010, Fig. 3 shows the individual storm paths on top of the storm track in these 2 years. In 1989, storm paths are concentrated along an axis tilted in a southwestnortheast direction stretching from Cape Hatteras towards the Nordic Seas. Almost no systems travel into the eastern subtropical North Atlantic. The storm track strength exceeds $60 \mathrm{hPa}^{2}$ over Newfoundland. Storm track anomalies relative to the climatological storm track (not shown) are positive throughout the North Atlantic except in the Labrador Sea and exceed $10 \mathrm{hPa}^{2}$ over Newfoundland and in the subpolar North Atlantic.

In comparison, individual storm paths in 2010 are less clustered with a number of storms travelling in a zonal fashion, penetrating the North Atlantic as far south as $35^{\circ} \mathrm{N}$. Occurrences in the Mediterranean basin increase, as does the frequency of storms reaching the southern European coast, whilst the number of storms travelling into the north-eastern
North Atlantic is greatly reduced. The core of the storm track, denoted by black contour lines, is displaced to the south by roughly $10^{\circ}$ relative to the climatological storm track. Pronounced deviations of more than $-30 \mathrm{hPa}^{2}$ occur in the core storm track region, whilst positive anomalies with magnitudes of roughly $10 \mathrm{hPa}^{2}$ are found south of the climatological storm track and west of Europe, notably in the Gulf of Biscay and off the Portuguese coast (not shown). This pattern suggests a general decrease in weather system intensity during the winter of 2010. The most striking feature, however, is the difference in the relative position and intensity of the storm track tail: Whilst storms in 1989 travel almost exclusively into the Nordic Seas, 2010 sees a number of storms travelling into the subtropical North Atlantic in a rather zonal fashion and reduced storm intensities in the subpolar North Atlantic. Note that the storm activity in the winters of 1989 and 2010 agrees well with those in the composites for negative and positive NAO years, respectively (Fig. 2).

\subsection{Near-inertial wind stress}

NIWSM represents the strength of the wind stress in the nearinertial band, i.e. the part of wind stress variability that is most efficient in exciting near-inertial currents and is thus closely related to WPI (Rath 2013). In our analysis domain, NIWSM
Fig. 3 Winter storm paths (JFM). a 1989 and b 2010. The line colour and style of a storm path corresponds to the maximum intensity of the system in terms of minimum core pressure. Thick red: $<960 \mathrm{hPa}$, yellow: $<980 \mathrm{hPa}$, dashed green: $<1000 \mathrm{hPa}$, dotted violet: $>1000 \mathrm{hPa}$. Grey background shading denotes the storm track as measured by the variance of band-pass-filtered sea level pressure variability (see Section 2.2). Black boxes as in Fig. 2d, e
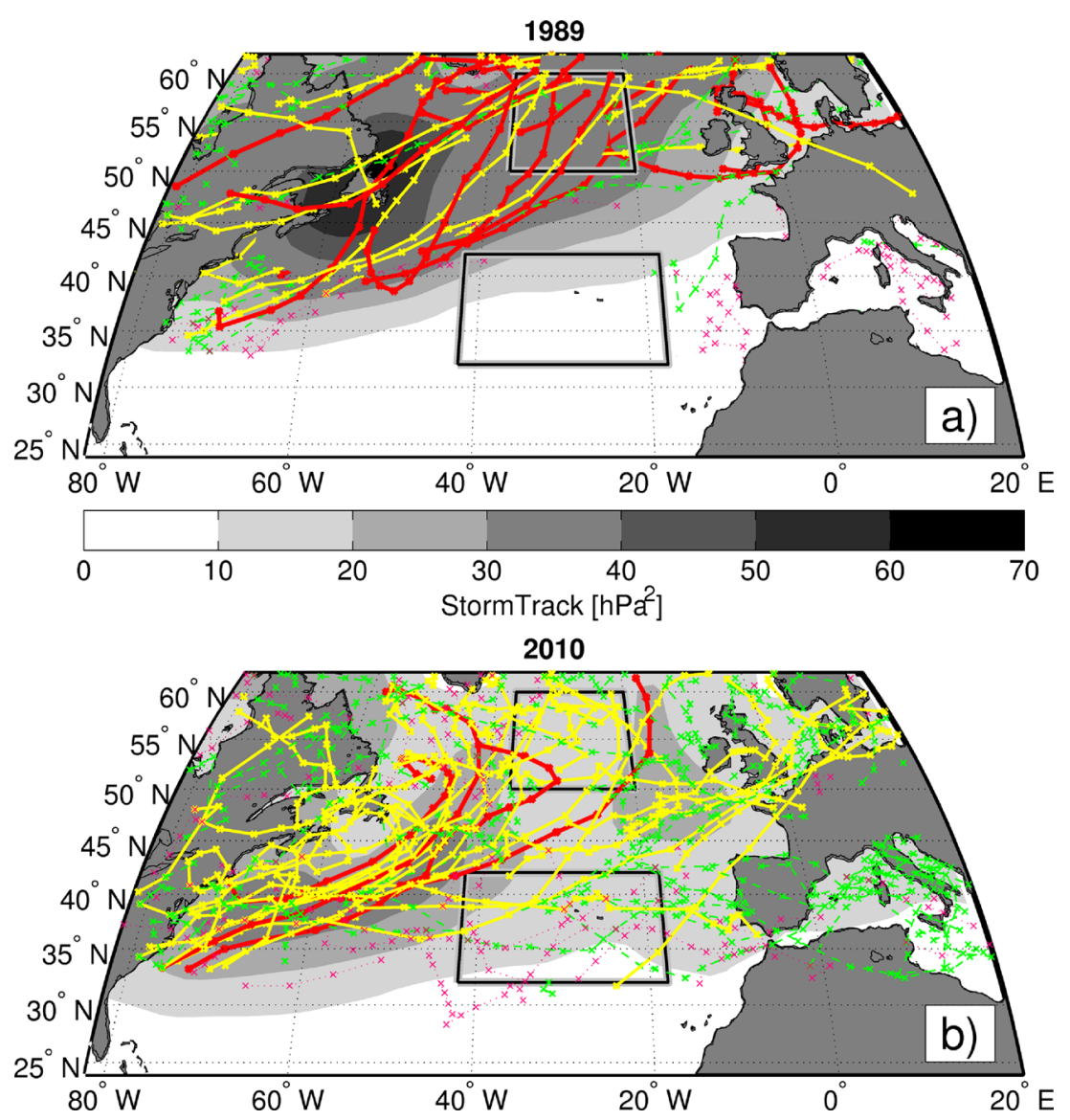
represents approximately $2-6 \%$ of the total wind stress magnitude. The ratio decreases towards the poles since the Coriolis parameter samples the wind stress spectrum at higher frequencies (cf. Section 3.3 for a more thorough discussion of this point).

In this section, we investigate the relationship between the mean NIWSM and the NAO. Note that due to the squaring of the wind stress components, NIWSM values for any location have a gamma-like distribution, with comparatively low values providing the bulk of the samples and a few high values exerting a strong influence on the arithmetic mean. Consequently, high mean NIWSM values may reflect strong intermittent events rather than continuously enhanced NIWSM throughout the entire season.

Figure 2a shows the climatological mean NIWSM for the period of 1980 to 2013 (colour shading). High values of climatological mean NIWSM are concentrated along an axis tilted in a southwest-northeast direction stretching from Cape Hatteras towards the Nordic Seas. There is a particularly enhanced patch of climatological mean NIWSM in an almond shape over the Gulf Stream between $35^{\circ}$ and $43^{\circ} \mathrm{N}$ and between $70^{\circ}$ to $45^{\circ} \mathrm{W}$, with maximum values reaching about $10 \times 10^{-3} \mathrm{~N} \mathrm{~m}^{-2}$. Note that the pattern of mean NIWSM generally resembles the storm track in shape but is displaced approximately $10^{\circ}$ to the south of it. A discussion of this feature is provided in Section 3.3.

Figure $2 \mathrm{~b}, \mathrm{c}$ shows the composites of mean NIWSM during different phases of the NAO. During positive NAO phases, mean NIWSM is strongly enhanced to the east of Newfoundland as well as in the subpolar ocean, reaching magnitudes of about $8.5 \times 10^{-3} \mathrm{~N} \mathrm{~m}^{-2}$. In the subtropical western North Atlantic, only slight changes occur relative to the climatology. During negative NAO phases, mean NIWSM in the subtropical North Atlantic is generally enhanced relative to both climatological conditions and positive NAO conditions, whereas mean NIWSM in the subpolar North Atlantic is visibly reduced, particularly relative to positive NAO conditions. Similar to climatological conditions, the pattern of mean NIWSM resembles that of the storm track but is displaced roughly $10^{\circ}$ to the south of it under both positive and negative NAO conditions.

Mean NIWSM in 1989 and 2010 (Fig. 2d, e) generally shares spatial patterns with the composites. In 1989, little NIWSM is found in the eastern subtropical North Atlantic, whereas mean NIWSM is greatly enhanced in the subpolar North Atlantic and penetrates further into the Nordic Seas. In contrast, mean NIWSM in 2010 is concentrated along a narrow zonal axis across the North Atlantic basin between $35^{\circ}$ and $45^{\circ} \mathrm{N}$. In accordance with the shifting of the storm track, mean NIWSM in the subpolar North Atlantic is now significantly reduced, whereas mean NIWSM in the eastern subtropical North Atlantic is strongly enhanced with values reaching $8 \times 10^{-3} \mathrm{~N} \mathrm{~m}^{-2}$. High values of mean NIWSM over the Gulf Stream appear largely unchanged in both years, albeit the patch in 2010 is displaced by approximately $5^{\circ}$ to the east.

\subsection{Southward displacement of mean NIWSM relative to the storm track}

Figure 2 shows that the storm track and regions of high mean NIWSM do not coincide. Rather, mean NIWSM is generally shifted by about $10^{\circ}$ to the south of the storm track. To understand this particular feature, we conducted a spectrum analysis of NCEP/NCAR wind stress in the region between $30^{\circ}$ and $60^{\circ} \mathrm{N}$ and $50^{\circ}$ and $40^{\circ} \mathrm{W}$ in the western North Atlantic.

Figure 4a shows the distribution of power spectral density in the near-inertial range. There are three noticeable features: (1) Surface wind stress in subtropical and mid-latitudes exhibits reddish amplitude spectra. (2) High-frequency wind stress variability is concentrated in the latitude band between $40^{\circ}$ and $50^{\circ} \mathrm{N}$. (3) The frequency at which the power spectral density starts to decrease ('cut-off frequency') depends on latitude, with cut-off periods increasing drastically towards the equator and less strongly towards the pole. Note that choosing a different time domain and/or a different longitude domain to conduct the analysis does not alter the results (not shown). Rath et al. (2014) conducted a similar analysis for the Southern Ocean and found features consistent with the results presented here.

In order to explain the offset between mean NIWSM and the storm track, attention needs to be paid to the near-inertial part of wind stress variability. This part of wind stress variability is tied to the local inertial frequency that varies with latitude. This variation, however, does not necessarily match the storm track, that is, synoptic variability on time scales of 2 to 6 days, as is demonstrated below. Figure $4 \mathrm{~b}$ shows the power spectral density of wind stress that corresponds to the inertial frequency ('inertial PSD'). Because the spectra of surface wind stress are red, longer inertial periods at lower latitudes end up effectively sampling greater wind stress variability. In fact, if the (red) wind stress spectra were uniform with latitude, variations of the inertial period with latitude would result in a near-monotonic decrease of the inertial PSD with latitude. This is illustrated in Fig. 4b for the wind stress spectrum at $37^{\circ} \mathrm{N}$. In reality, however, the high-frequency PSD associated with the storm track peaks in the mid-latitudes and decreases towards either side. As a result, mean NIWSM is displaced approximately $10^{\circ}$ to the south of the climatological storm track instead of coinciding with it.

\section{Results of ocean model experiments}

In this section, we examine WPI to near-inertial motions in the winters of 1989 and 2010, using the high-resolution model of the North Atlantic. 

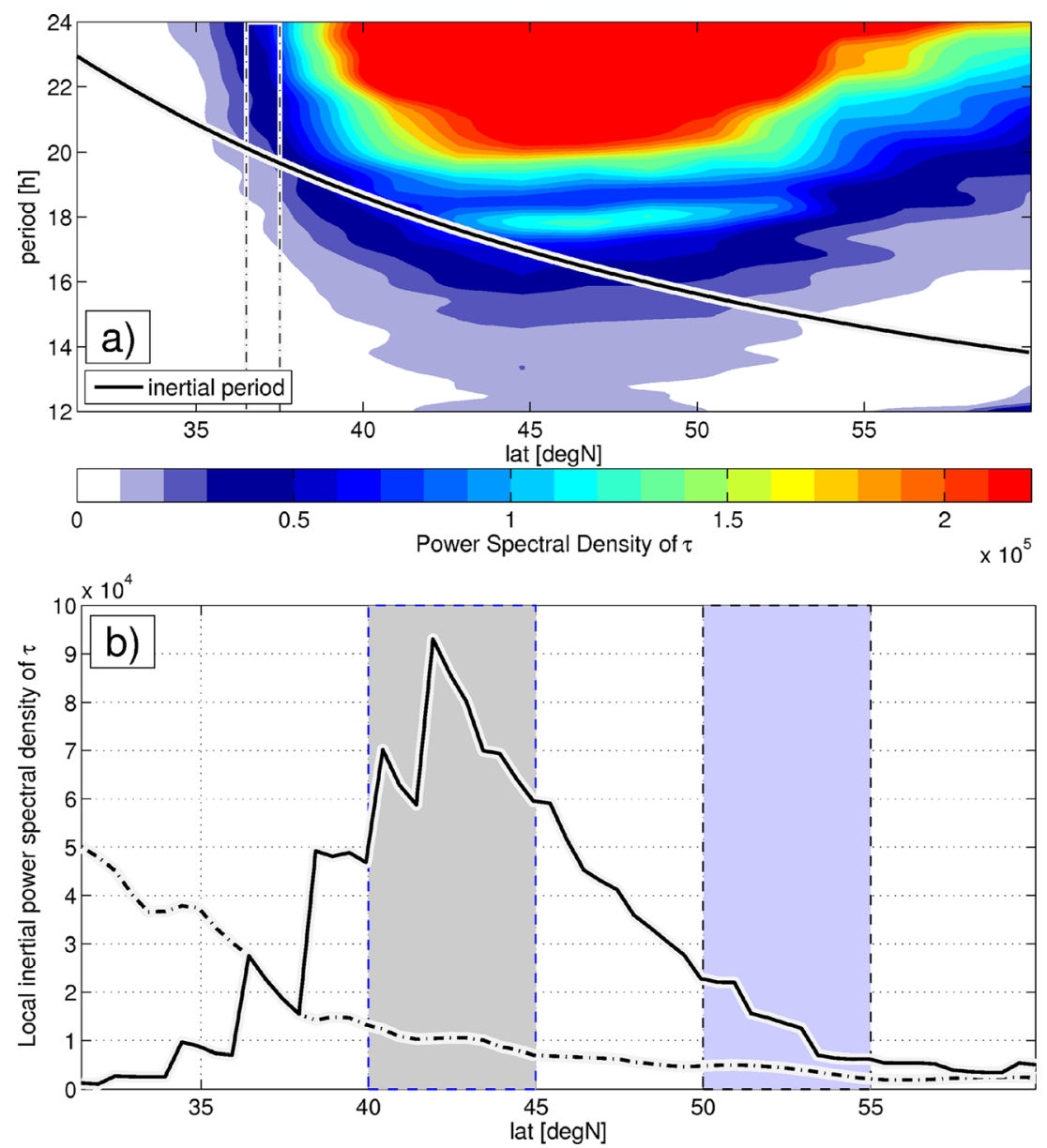

Fig. 4 a Surface wind stress power spectral density (PSD) in the North Atlantic subtropical and mid-latitudes. The solid line corresponds to the local inertial period. The dash-dotted rectangle marks the area which serves to provide the constant wind stress spectrum in b) (approximately $37^{\circ} \mathrm{N}$ ). b Power spectral density (PSD) of near-inertial wind stress ('inertial PSD') as a function of latitude (solid black line). Inertial PSD was obtained by following the inertial frequency in a and charting the corresponding PSD on the $y$-axis. To highlight the impact of the variations of surface wind stress spectra with latitude on inertial PSD, the dash-dotted line shows the inertial PSD resulting from latitudinally homogenous surface wind stress spectra. The employed wind stress spectrum corresponds to the climatological spectrum at approximately $37^{\circ} \mathrm{N}$ and is marked by a dash-dotted rectangle in a. Shaded blue and grey areas correspond to the regions of enhanced mean NIWSM and the North Atlantic climatological storm track, respectively (cf. Fig. 2d, e)

\subsection{WPI in 1989 and 2010}

Figure 5 shows the spatial distributions of winter-mean WPI produced by wind stress forcing in 1989 and 2010, respectively. Similarities between the patterns of WPI and NIWSM are obvious in both years.

High values of WPI in 1989 are concentrated along an axis tilted in a southwest-northeast direction stretching from Cape Hatteras towards the Nordic Seas, although the magnitude of WPI in the subpolar region is much less pronounced than that of NIWSM. Maximum WPI with values of up to $1.4 \mathrm{~mW} \mathrm{~m}^{-2}$ (where $1 \mathrm{~mW} \mathrm{~m}^{-2}=10^{-3} \mathrm{~W} \mathrm{~m}^{-2}$ ) are found over the Gulf Stream in the region between $35^{\circ}$ and $45^{\circ} \mathrm{N}$ and between $70^{\circ}$ and $40^{\circ} \mathrm{W}$, corresponding to the patch of high mean NIWSM (cf. Fig. 2d). A weak secondary centre of high WPI appears to the west of the UK, again matching increased
NIWSM. Note that these patches of large NIWSM in the subtropical and subpolar North Atlantic, although of similar strength, differ significantly in their efficiency in producing WPI (cf. Figs. 2 and 5). It is also worth pointing out that there is a hotspot of WPI directly off the African coast at $30^{\circ} \mathrm{N}$ with maximum magnitude reaching $1.7 \mathrm{~mW} \mathrm{~m}^{-2}$.

In 2010, when the NAO index is strongly negative, WPI is found to be confined mostly to the south of $50^{\circ} \mathrm{N}$ in the subtropical North Atlantic. North of $50^{\circ} \mathrm{N}$, the North Atlantic is basically void of WPI. This pattern of WPI is again similar to that of mean NIWSM (Fig. 2e) and results from the southward shift of the storm track in 2010. In the subtropical North Atlantic, two regions of enhanced WPI emerge: The first region coincides with the patch of highest mean NIWSM south of the Gulf Stream. The second region is associated with a weak secondary centre of NIWSM in the eastern subtropical 
Fig. 5 Time-averaged wind power input to surface mixed layer inertial currents in $10^{-3} \times$ $\mathrm{W} \mathrm{m}{ }^{-2}$ for JFM a 1989 and $\mathbf{b}$ 2010. Black boxes as in Fig. 2d, e

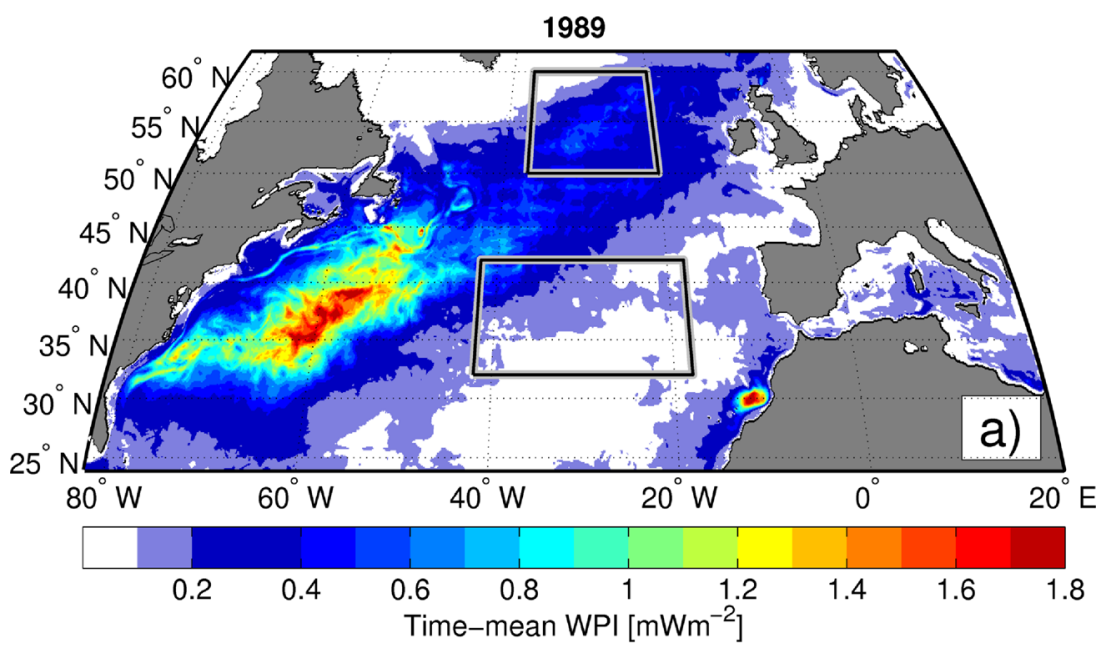

2010

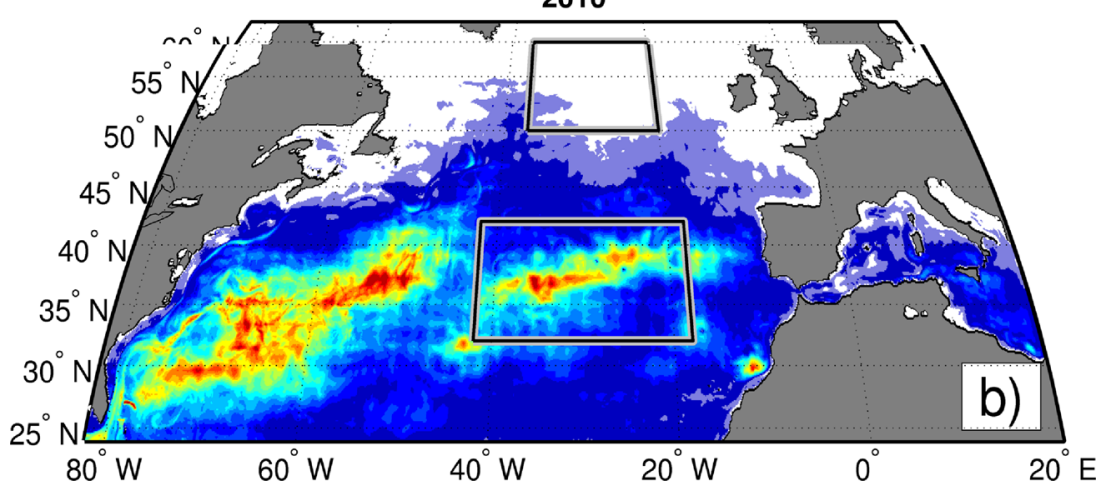

North Atlantic. The magnitude of WPI in both regions reaches values of roughly $1.4 \mathrm{~mW} \mathrm{~m}{ }^{-2}$. The confined patch of enhanced WPI off the African coast remains unchanged relative to 1989 , suggesting that the occurrence of this hotspot of WPI is independent of the phase of the NAO. Further analysis reveals that this feature is associated with the land-sea breeze: At $30^{\circ} \mathrm{N}$, the diurnal frequency of the land-sea breeze coincides with the inertial frequency, which strongly enhances WPI there (not shown).

Integrating over the North Atlantic basin, ${ }^{2}$ WPI to near-inertial motions in 1989 is about $6.48 \mathrm{GW}$ $\left(1 \mathrm{GW}=10^{9} \mathrm{~W}\right)$ in comparison to $9.64 \mathrm{GW}$ produced in 2010. This result is unexpected, since Figs. 2 and 3 suggest that storms in 2010 are less intense compared to 1989. Furthermore, extending the domain shown in Fig. 3 to encompass the higher latitudes of the Nordic Seas additionally suggests that fewer storms occur in the North Atlantic in 2010 (not shown). However, whether the difference in storm frequencies between the 2 years is statistically significant has not been investigated.

\footnotetext{
2 The North Atlantic basin here refers to the region between $25^{\circ}$ and $65^{\circ}$ $\mathrm{N}$ and between $90^{\circ} \mathrm{W}$ and $0^{\circ} \mathrm{E}$
}

\subsection{Enhanced WPI in the subtropics}

Comparing mean NIWSM, the storm track and WPI in 1989 and 2010 (cf. Figs. 2, 3 and 5, respectively) suggests that NIWSM is more efficient in generating WPI to near-inertial motions in the subtropics than in the subpolar region. To illustrate this point more clearly, Table 1 shows area-averaged mean NIWSM and WPI in both the subtropical and subpolar North Atlantic for 1989 and 2010. The areas of interest, marked as black boxes in Fig. 2d, e, are regions that feature enhanced WPI in the eastern North Atlantic either in 1989 or

Table 1 Area averages of NIWSM (top) and WPI (bottom) in the subpolar and subtropical box, both for 1989 and 2010. The geographical position and extent of the boxes are shown as black contours in Fig. 2 and subsequent maps (Figs. 3, 5 and 6). The subtropical box encompasses the ocean between $42^{\circ}$ and $18^{\circ} \mathrm{W}, 32^{\circ}$ and $42^{\circ} \mathrm{N}$. The subpolar box encompasses the ocean between $37^{\circ}$ and $20^{\circ} \mathrm{W}, 50^{\circ}$ and $60^{\circ}$ $\mathrm{N}$

\begin{tabular}{llll}
\hline & Latitude & 1989 & 2010 \\
\hline NIWSM $\left(10^{-3} \times \mathrm{N} \mathrm{m}^{-2}\right)$ & Subpolar & 8.29 & 2.92 \\
& Subtropical & 2.78 & 6.10 \\
\multirow{2}{*}{ WPI $\left(10^{-3} \times \mathrm{W} \mathrm{m}^{-2}\right)$} & Subpolar & 0.33 & 0.03 \\
& Subtropical & 0.13 & 0.54 \\
\hline
\end{tabular}


2010. Although mean NIWSM is much more enhanced in the subpolar box in $1989\left(8.29 \times 10^{-3} \mathrm{~N} \mathrm{~m}^{-2}\right)$ than in the subtropical box in $2010\left(6.10 \times 10^{-3} \mathrm{~N} \mathrm{~m}^{-2}\right)$, WPI is greater in the subtropical box in $2010\left(0.54 \mathrm{~mW} \mathrm{~m}^{-2}\right)$ than in the subpolar box in $1989\left(0.33 \mathrm{~mW} \mathrm{~m}^{-2}\right)$. Here, we use solutions of the slab model to highlight several key parameters and processes that may contribute to enhanced WPI in the subtropical ocean whilst bearing in mind the limitations of such a simple model (e.g. Plueddemann and Farrar 2006; Rath et al. 2014).

The momentum equation of the slab model is usually given in complex notation:

$\frac{\mathrm{d} Z}{\mathrm{~d} t}+\omega Z=\frac{T}{H}$,

where $Z=u+i v$ is the complex current strength, $T=\left(\tau_{x}+i \tau_{y}\right)$ $\rho^{-1}$ is associated with the complex wind stress, $H$ is the mixed layer depth and $\omega=r+i f$, where $f$ is the local Coriolis parameter and $r^{-1}$ is the linear damping time scale that is usually set to be 2 to 10 days (D'Asaro 1985). Variations of the mixed layer depth are neglected here for simplicity. The general solution to this problem is given by

$Z(t)=\frac{\int T(t) e^{\omega t} \mathrm{~d} t+c}{H e^{\omega t}}$,

where $c$ is an unknown constant to be determined. Note that $Z(t)$ includes both Ekman and near-inertial current components, i.e. $Z(t)=Z_{\mathrm{E}}(t)+Z_{\mathrm{I}}(t)$, where $Z_{\mathrm{E}}(t)$ and $Z_{\mathrm{I}}(t)$ are the Ekman- and near-inertial components of the current, respectively.

Consider the situation where the ocean is initially at rest $(t=$ 0 ) and a constant meridional wind stress of amplitude $T_{0}$ is suddenly switched on for a time period $L$, i.e.:

$T(t)=\left\{\begin{array}{cc}i T_{0} & 0<t \leq L \\ 0 & t>L\end{array}\right.$.

The solution for the inertial currents, $Z_{\mathrm{I}}(t)$-i.e. excluding the Ekman component of the current-is obtained by substituting Eq. (3) into Eq. (2):

$Z_{\mathrm{I}}(t)=\left\{\begin{array}{cc}-\frac{i T_{0}}{\omega H} e^{-\omega t} & 0<t \leq L \\ \frac{i T_{0}}{\omega H}\left(e^{\omega L}-1\right) e^{-\omega t} & t>L\end{array}\right.$

which, in the limit of $r \ll|f|$, simplifies to

$Z_{\mathrm{I}}(t)=\left\{\begin{array}{cc}-\frac{T_{0}}{f H} e^{-i f t} & 0<t \leq L \\ \frac{T_{0}}{f H}\left(e^{i f L}-1\right) e^{-i f t} & t>L\end{array}\right.$.
WPI to near-inertial motions associated with this single wind event is finally given by

$\mathrm{WPI}=\operatorname{Re}\left[\int_{0}^{L} Z_{\mathrm{I}}(t) T(t) \mathrm{d} t\right]=\frac{T_{0}^{2}}{f^{2} H}(1-\cos f L)$

Equation (6) states that WPI for a single event is made up of two components: The 'base WPI' is depending on the wind stress, the latitude and the depth of the underlying mixed layer. Strong wind stress in low latitudes on shallow mixed layers is prone to result in large values of the base WPI in accordance with the literature on near-inertial currents and WPI to them. The base WPI in turn is modulated by the length of the wind event. These simple results help to identify several factors that help to explain why WPI favours the subtropics on seasonal time scales (JFM in this paper):

1. Coriolis parameter The inverse quadratic dependence of WPI on the Coriolis parameter suggested by Eq. (6) originates from two contributions. First, the strength of nearinertial currents is inversely proportional to $|f|$ as shown in Eq. (5), which means that similar wind events are able to excite stronger near-inertial currents at low latitudes compared to high latitudes. This is clearly illustrated in Fig. 6, where the magnitude of near-inertial currents in 1989 is more pronounced in the subtropics, although mean NIWS $\mathrm{M}$ is much weaker in the subtropics in that year (Fig. 2d).

The second, but subtler, contribution stems from the period of near-inertial currents, i.e. the inertial period. This is most easily understood by considering a one-dimensional surface current that varies sinusoidally in time and is driven by a constant, non-zero wind stress (e.g. the horizontal or zonal component of a near-inertial oscillation). WPI to this current is simply an integral of a sinusoidal curve, the magnitude of which is proportional to its period. Physically, ocean currents that oscillate at longer periods allow the wind stress to inject more power during the positive phase of WPI-i.e. when the directions of the wind stress and the current coincide-and take out more power during the negative phase of WPI as well. Since the inertial period increases with decreasing latitude, WPI at low latitudes has the potential to reach higher amplitudes subject to similar wind forcing, because positive contributions to WPI occur on longer times. The strong dependence of WPI on the Coriolis parameter, we believe, is the main reason behind the greater WPI produced in 2010 than 1989, because the storm track and its associated near-inertial wind stress are shifted southward to lower latitudes in 2010, even though the basin-averaged NIWSM is much weaker in 2010 than 1989. 
Fig. 6 Strength of surface nearinertial currents in a 1989 and b 2010. 'Surface' in this case refers to the first level of the ocean model. The unit is meters per second. Note that the colour bar is logarithmic. Black boxes as in Fig. 2d, e

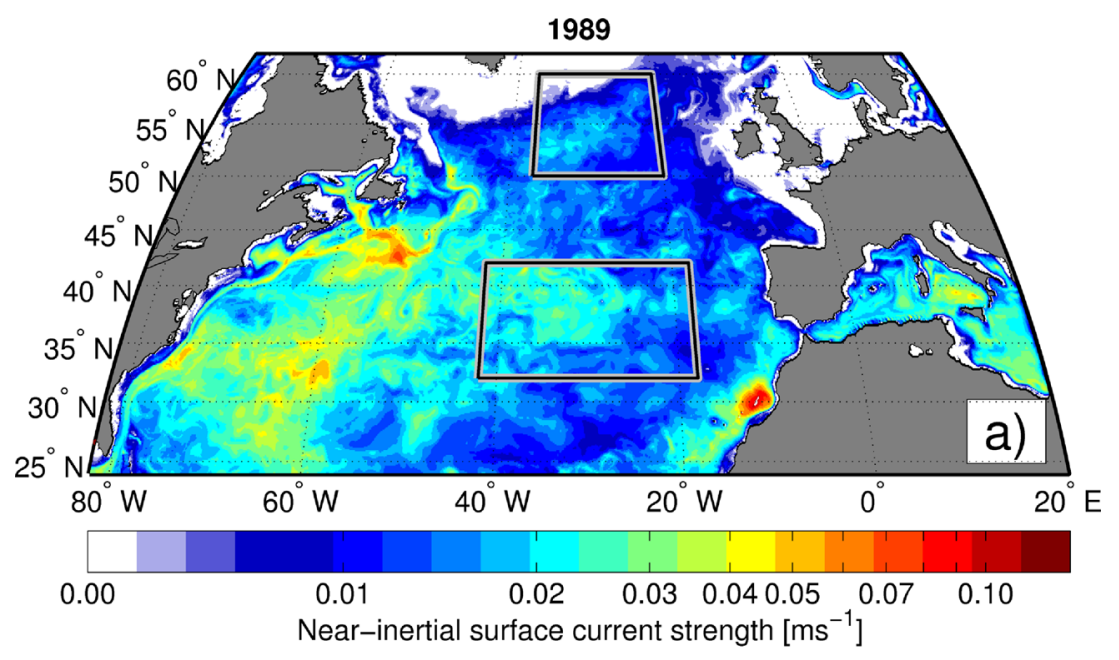

2010

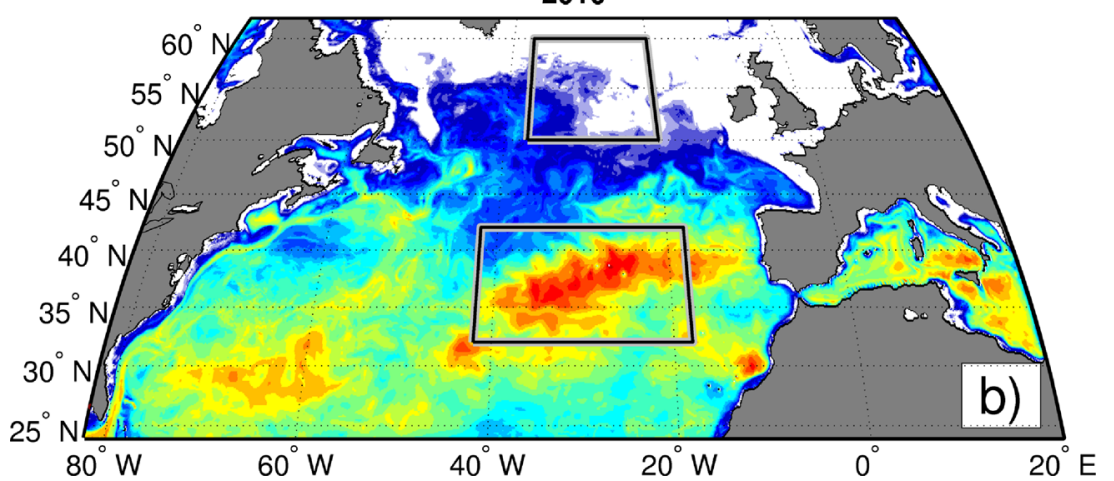

2. Mixed layer depth In the slab model, near-inertial currents are assumed to mix instantaneously over the prescribed mixed layer depth. As a consequence, the strength of near-inertial currents as well as WPI is inversely proportional to the mixed layer depth. This conclusion, however, has recently been called into question. For example, Rath et al. (2014) found that the vertical homogenisation of near-inertial currents in the surface mixed layer often takes longer than the duration of these strong wind events themselves, rendering the WPI insensitive to the mixed layer depth in their primitive-equation model. Nevertheless, shallower mixed layer depths in the subtropics could potentially enhance WPI production there. However, investigating in detail the impact of the mixed layer depth on WPI is beyond the scope of this study and will be the subject of a future investigation.

3. Cancellation effect The cancellation effect here refers to the fact that instantaneous WPI-i.e. the scalar product of wind stress and near-inertial surface current at a given time - can be either positive or negative, depending on the relative directions between the wind stress and surface near-inertial currents. As a result, WPI integrated over a wind event or the entire season inevitably involves cancellations between positive and negative contributions to WPI. This process is qualitatively captured by the factor $(1-\cos f L)$ in Eq. (6), which modulates WPI depending on the length of the wind event. Shortlasting intermittent wind events-i.e. up to half the inertial period, during which the factor $(1-\cos f L)$ increases from 0 to 2 -are most efficient in generating net WPI by avoiding cancellations with the negative WPI that follows.

One way to measure the cancellation effect is to calculate the 'cancellation ratio' by dividing the sum of all positive contributions to WPI by (the modulus of) that of all negative contributions to WPI during one season. Note that in this configuration, large cancellation ratio values correspond to decreased actual cancellation between positive and negative contributions to WPI. We chose this definition because it relates directly to WPI: the more the cancellation ratio exceeds 1 , the more efficient is the WPI. Figure 7 shows the zonally averaged cancellation ratio in the eastern Atlantic for the winters of 1989 (red) and 2010 (blue). The cancellation ratio in the subtropics in 2010 is found to be higher than that in 1989. This is related to the enhanced intermittency 
Fig. 7 Zonal average of the cancellation ratio (positive contributions to WPI divided by modulus of negative contributions to WPI). The zonal strip for the analysis is $40^{\circ} \mathrm{W}$ to $10^{\circ} \mathrm{W}$

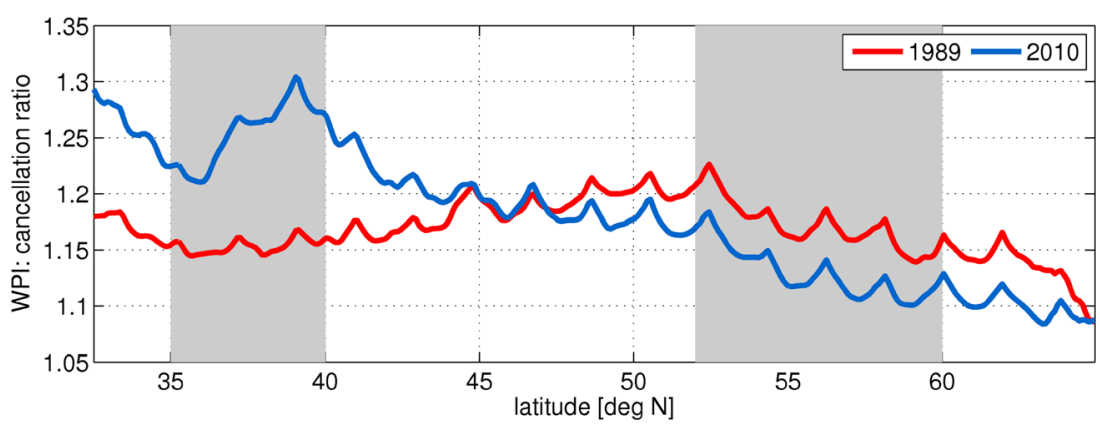

of storms indicated by Fig. $3^{3}: 2010$ sees a number of storms in the subtropics that introduce welldefined peaks in the NIWSM-time series at individual locations, increasing the intermittency of NIWS M events. In contrast, no storm passes this region in 1989. Consequently, the intermittency of NIWSM events is very low because local NIWSM is regulated by the prevailing wind system.

Intermittency of wind events enhances the cancellation ratio by the following mechanism: In the subtropical North Atlantic, intermittent wind events due to storms can generally be expected to be weaker than their more frequent counterparts in the mid-latitude and subpolar North Atlantic. Weak wind events generate weak near-inertial oscillations. These near-inertial oscillations are apt to abate quickly. Subsequent wind events can be expected to meet no, or only very weak, pre-existing near-inertial oscillations, implying that any wind event basically acts on an 'empty' ocean in the sense that it is void of strong near-inertial currents. This, in turn, renders the initial — and generally biggest contribution to-WPI positive. Note that although preexisting near-inertial currents do not necessarily render initial WPI contributions negative, they allow for this possibility. This is not the case in the 'empty ocean' scenario, i.e. the absence of pre-existing near-inertial currents raises the chance of enhancing the cancellation ratio, increasing the effectiveness of WPI to near-inertial currents. Thus, regions that are struck by NIWSM events only rarely are prone to exhibit enhanced cancellation ratios. This hypothesis is confirmed by investigating the spatial distribution of the cancellation ratio both in 1989 and 2010 and comparing it to Figs. 2 and 3 (not shown).

4. Other potential contributing processes The wind stress on the southern side of the storms in the northern hemisphere is believed to favour the generation of near-inertial currents. Firstly, the cold front, the most efficient weather phenomenon to trigger strong WPI events according to

\footnotetext{
${ }^{3}$ A common measure of the intermittency of a given time series is kurtosis. Indeed, the spatial distribution of NIWSM kurtosis supports the following argument (not shown).
}

D'Asaro (1985), is usually located on the southern side of a storm. Furthermore, for symmetric translating storms, the wind vector at a fixed location rotates clockwise in time on the southern side of the storm and anti-clockwise on the northern side. The clockwise rotation coincides with the rotational direction of inertial oscillations in the northern hemisphere and therefore favours WPI (e.g. Chang and Anthes 1978; Price 1981; Greatbatch 1983).

In summary, Eq. (6) identifies a number of factors that favour WPI production in the subtropics. We believe that, amongst these factors, the variation of the Coriolis parameter with latitude is dominant. Note that each of the other factors - a possible influence from the mixed layer depth, enhanced intermittency of wind events in the subtropics, the impact of the symmetry of single storms - is apt to enhance WPI in the subtropics independently. Thus, when the storm track is shifted towards lower latitudes, the mechanisms presented above act together and enhance WPI relative to the case when the storm track resides farther north.

\section{Interannual variability of WPI in the North Atlantic}

\subsection{Mean NIWSM as an atmospheric proxy for WPI}

To investigate the interannual variability of WPI on a basinwide scale, we now establish statistical relationships between WPI and atmospheric wind forcing as a means of estimating seasonal WPI. We follow a recent study by Rath et al. (2014) who found time-integrated NIWSV to serve as a useful proxy for WPI in the Southern Ocean.

Here we use the output from the North Atlantic model to test two possible proxies for building linear regression models for seasonally averaged WPI during JFM (or simply 'seasonal' for the remainder of the paper). Firstly, we use seasonal NIWSV following Rath et al. (2014). Secondly, we use seasonal NIWSM based on the similar patterns of seasonal WPI and seasonal NIWSM evident in Figs. 5 and 2, respectively, and commented on in Section 4.1. Motivated by the findings of Section 4.2-i.e. that the relationship between seasonal 
WPI and seasonal NIWSM depends strongly on latitude - we conduct regression analysis for three separate latitude bands, with the low, mid and high latitude bands covering the North Atlantic for $\varphi<35^{\circ} \mathrm{N}, 35^{\circ} \mathrm{N}<\varphi<50^{\circ} \mathrm{N}$ and $\varphi>50^{\circ} \mathrm{N}$, respectively. To increase the number of valid data points, WPI and NIWSM/NIWSV are binned into $5^{\circ}$ longitude $\times 5^{\circ}$ latitude boxes and area-averaged prior to regression.

Figures 8 and 9 show the regressions of WPI against mean NIWSM and mean NIWSV, respectively. For both proxies, the slope of the linear regression models decreases drastically with increasing latitude, confirming the higher sensitivity of WPI to near-inertial wind forcing at lower latitudes. Note that for the mean NIWSM models, the ratio of slopes between low latitudes and high latitudes is about 4.3. This is greater than the ratio of slopes that would arise from the $f^{-2}$ dependence alone predicted by Eq. (6) (approximately 3), suggesting that additional effects are at work that further enhance WPI in the subtropics (see Section 4.2 for a discussion of these effects).

To assess whether the linear models are sensitive to the year chosen to derive the model, Figs. 8 and 9 show both the
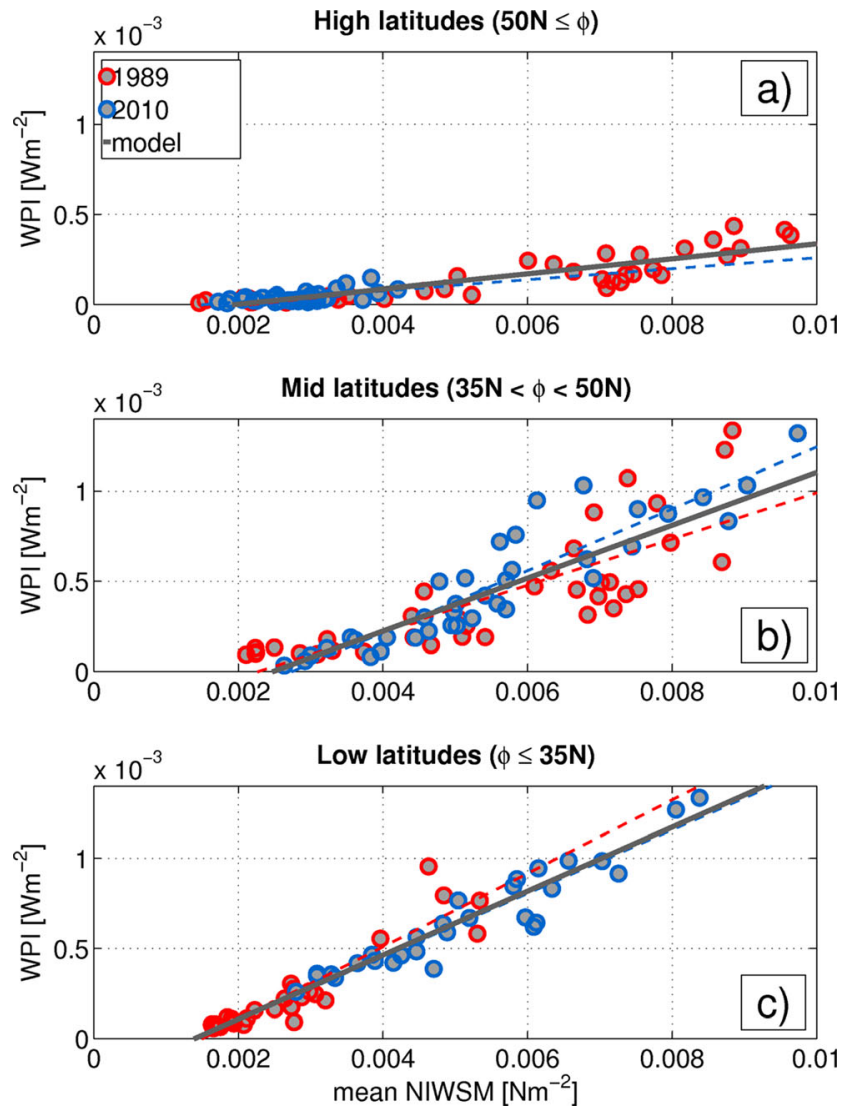

Fig. 8 First-order linear regression of WPI on mean NIWSM for a high latitudes $\left(\varphi>50^{\circ} \mathrm{N}\right)$, b mid-latitudes $\left(35^{\circ} \mathrm{N}<\varphi<50^{\circ} \mathrm{N}\right)$ and $\mathbf{c}$ low latitudes $\left(\varphi<35^{\circ} \mathrm{N}\right)$. Mean NIWSM and WPI data have been averaged into $5^{\circ}$ longitude $\times 5^{\circ}$ latitude bins prior to regression. Red: 1989 , blue: 2010 . Dashed lines correspond to the linear regression models based on the respective year (single-year models), solid grey lines to the model derived from both years (2-year models). The 2-year models are used for estimating total WPI for 1980 to 2013 (Fig. 10)
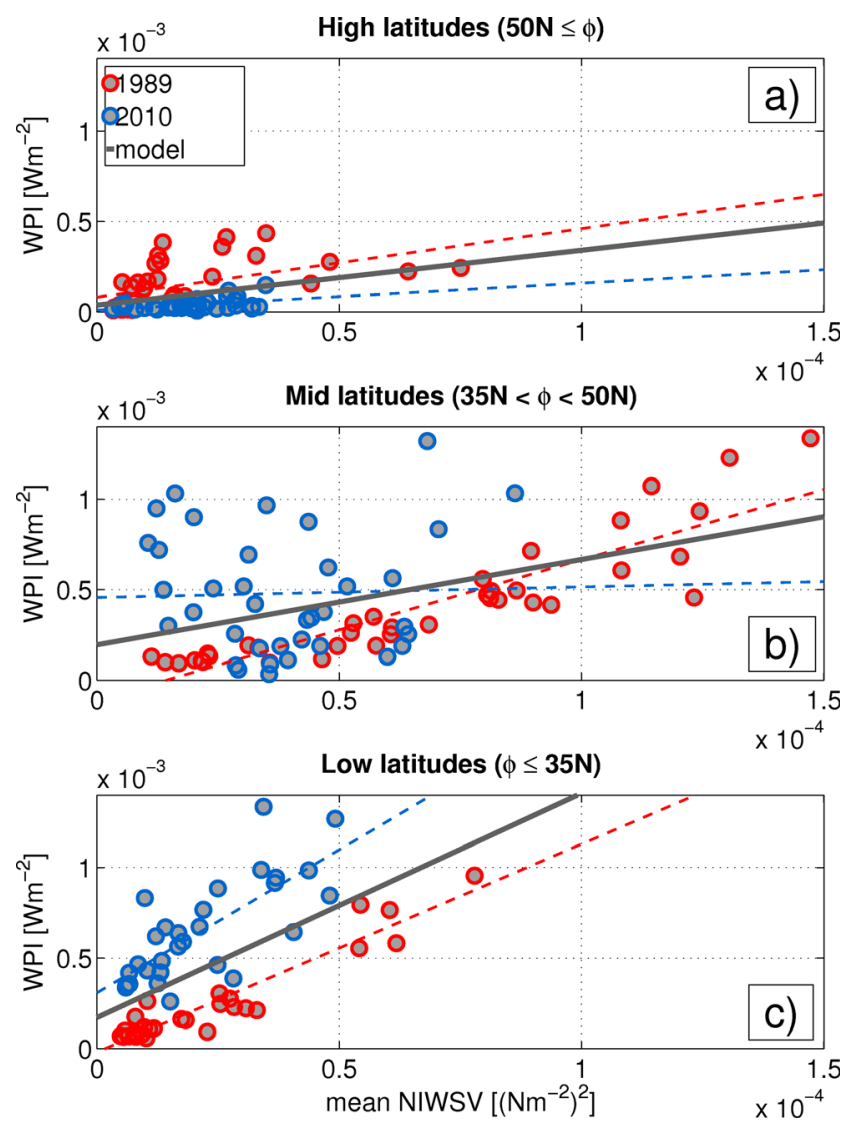

Fig. 9 Same as Fig. 8, but for mean NIWSV

models based on a single year (single-year models, dashed coloured lines) and the model derived from using both years (2-year models, solid grey line). It is obvious that the regression parameters for the NIWSV models are rather sensitive to the year chosen for building the model and result in singleyear models that differ substantially from the 2-year model.

For the mean NIWSM models on the other hand, the single-year models are barely distinguishable from the 2year models for small and moderate NIWSM and result in deviations that hardly exceed $10 \%$ for the strongest NIWS $\mathrm{M}$ events in mid- and low latitudes. (Deviations for the highlatitude case are marginal.) However, since we can assume that the physics controlling the WPI-NIWSM relationship on seasonal time scales do not change from year to year and we provided sufficient data points to build robust linear regression models for a given latitude band, it is not surprising that there is little variation in the model parameters between the single-year models and the 2-year models. Note that this finding lends confidence to our analysis of interannual variability of WPI below: Since the years chosen to build the models were characterised by extreme NAO phases, we can expect single-year models for any other year in our analysis period to lie between the two single-year models for 1989 and 2010, i.e. relatively close to our 2-year models. We are confident that our 2-year models - exactly because they were trained during 
complementary extreme NAO conditions - do well in capturing the WPI-NIWSM relationship for moderate NAO years as well. For the remainder of the study, unless explicitly stated otherwise, our linear models refer to the 2-year models of the respective latitude band.

One concern about the NIWSM models is tied to very weak NIWSM. It can be seen from Fig. 8 that, for all latitude bands, the regression line does not pass through the origin $(0,0)$, indicating that the WPI predicted by the regression model for very weak seasonal NIWSM would be unrealistic. We are aware of this issue but chose not to use linear regression of higher order (e.g. a quadratic fit) for two reasons: Firstly, this issue exclusively concerns the weakest seasonal NIWSM events. These events occur only rarely, and since they are associated with the lower tail of the distribution of seasonal NIWSM, their impact on total WPI can be expected to be marginal at best. Secondly, Fig. 8 confirms that seasonal NIWSM both in 1989 and 2010 hardly falls below values of $2 \times 10^{-3} \mathrm{~N} \mathrm{~m}^{-2}$, i.e. our data provides no samples to accurately estimate the relationship between NIWSM and WPI close to the origin. Speculating about a quadratic fit being more appropriate based on the model fit for very weak NIWSM thus would remain guesswork.

To assess the performance of our linear regression models more quantitatively, we calculated the (normalised) rootmean-square error ((N)RMSE) for each model. The NRMSE is the RMSE divided by the range of the predicted variable, i.e. $\mathrm{WPI}_{\max }-\mathrm{WPI}_{\min }$ in the case of this study. To estimate the (N)RMSE of our models, we used leave-one-out crossvalidation (LOO-CV). This method is commonly employed to validate statistical models and is presented in several statistics textbooks, e.g. Von Storch and Zwiers (1999). For a simple version of the LOO-CV, we successively build linear models of WPI, leaving out one $5^{\circ}$ longitude $\times 5^{\circ}$ latitude box (one data point). Each box is left out once, and the difference between the model and the 'true' value obtained from the North Atlantic model run is calculated. This corresponds to the error of the linear regression model for this specific model and this specific box. Squaring, averaging and subsequent extraction of the square root of the individual errors yield the RMSE.

Table 2 shows the RMSE and NRMSE of predicted WPI of our linear regression models for each latitude band. NRMSEs for the mean NIWSM and mean NIWSV models are on average 11 and $23 \%$, respectively. This clearly suggests that mean NIWSM is a more suitable proxy for WPI in the framework of our linear regression approach. Note that both the NRMSE values and the models shown in Fig. 9 simply state that, in the North Atlantic, the NIWSM-WPI relationship is more prone to be captured by linear regression models of order 1 than the NIWSV-WPI relationship. With respect to the study by Rath et al. (2014), this result is surprising. Rath et al. (2014) found NIWSV to be a good proxy to WPI in the Southern Ocean. It is possible that the different results presented in this study are related both to the fact that a different ocean basin is being analysed and that different ocean models were used. A particularly important difference could be that different vertical mixing schemes are used.

Note that employing different regression strategies might lead to different results. For this study, however, we chose mean NIWSM as the atmospheric proxy for WPI and employ the (2-year) models presented in Fig. 8 to estimate WPI for the period 1980 to 2013 .

\subsection{Interannual variability}

Figure 10 shows the time series of WPI in the three latitude bands defined above as well as basin-wide WPI from 1980 to 2013. Interesting features arise which are discussed below.

Time series of WPI at low and high latitudes (Fig. 10b) exhibit large interannual variability and are negatively correlated with each other $(-0.75$; significant at $95 \%$ confidence level using Student's $t$ test). This suggests a seesaw-like behaviour with enhanced subtropical WPI coinciding with reduced subpolar WPI and vice versa. Furthermore, WPI in these two latitude bands is significantly correlated with the
Table 2 Overview over linear models for WPI based on mean NIWSM (top) and mean NIWSV (bottom). RMSE and NRMSE were estimated from a leave-one-out cross-validation. NRMSE is the normalised RMSE, i.e. RMSE divided by the data range, that is: $\mathrm{WPI}_{\max }-\mathrm{WPI}_{\min }$. Latitude ranges for the single model classes were as follows: low: $\varphi<35^{\circ} \mathrm{N}$, mid: $35^{\circ} \mathrm{N}<\varphi<50^{\circ} \mathrm{N}$, and high: $50^{\circ} \mathrm{N}<\varphi$. Units of the slope parameter are watts per square meter/newtons per square meter and watts per square meter/(newtons per square meter) ${ }^{2}$ for NIWSM and NIWSV, respectively

\begin{tabular}{lllrrr}
\hline & Latitude & Average WPI $\left(\times 10^{-3} \mathrm{~W} \mathrm{~m}^{-2}\right)$ & RMSE $\left(\times 10^{-5} \mathrm{~W} \mathrm{~m}^{-2}\right)$ & NRMSE (\%) & Slope \\
\hline \multirow{2}{*}{ NIWSM } & Low & 4.48 & 9.63 & 0.178 \\
& Mid & 4.47 & 17.71 & 14 & 0.150 \\
& High & 0.94 & 4.70 & 11 & 0.037 \\
\multirow{2}{*}{ NIWSV } & Low & & 26.48 & 21 & 23 \\
& Mid & & 29.95 & 24 & 2.70 \\
& High & & 10.05 & 3.02 \\
\hline
\end{tabular}


Fig. 10 Time series of WPI based on mean NIWSM (the linear model is presented in Fig. 8). a Entire basin (i.e. sum of WPI in the three latitude bands shown below); b high (red) and low latitudes (blue), note that the $y$-axis for these two quantities are not identical and that WPI in the low latitudes is up to an order of magnitude larger than in the high latitudes; and $\mathbf{c}$ mid-latitudes. Latitude belts are the same as in Figs. 8 and 9. Solid lines denote the WPI estimate, dashed lines denote RMSEs that were derived from leave-one-out crossvalidation
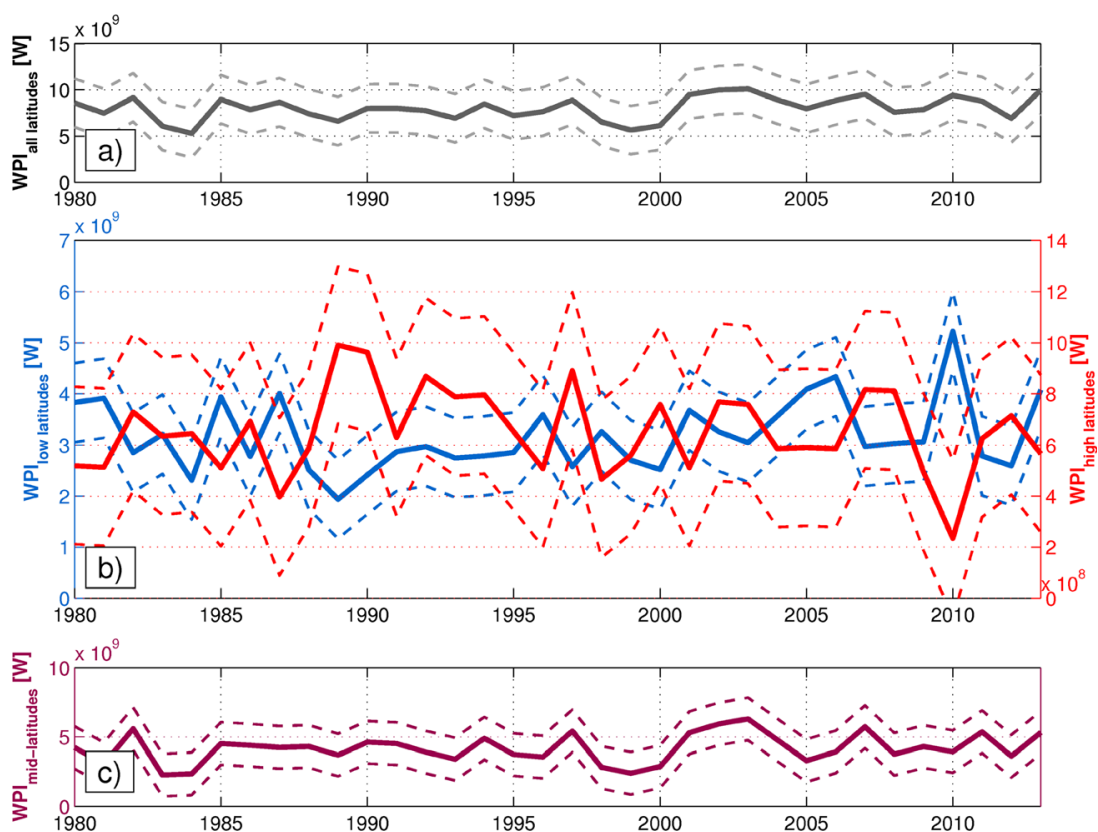

$\mathrm{NAO}$, with correlation coefficients of -0.87 and 0.81 for low and high latitudes, respectively. This is consistent with the discussion of the influence of the NAO on the storm track and NIWSM presented in Section 3: A shift of the storm track into the Nordic Seas under positive NAO conditions and into the subtropics under negative NAO conditions results in a corresponding meridional shift of mean NIWSM as well as WPI.

WPI at mid-latitudes (Fig. 10c) is not significantly correlated to the NAO. This implies that slight shifts in the position of the core storm track (cf. e.g. Fig. 3 for the storm track and Fig. 5 for the corresponding western Atlantic WPI pattern) have little impact on basin-wide WPI.

Lastly, basin-wide WPI (Fig. 10a) is rather weakly but still significantly correlated with the NAO at the $95 \%$ level (correlation coefficient is -0.42 ). The negative correlation is due to an asymmetric impact of positive and negative NAO conditions on basin-wide WPI: Whilst basin-wide WPI during positive NAO conditions is not significantly different from climatological conditions, basin-wide WPI during negative NAO conditions is significantly greater. This asymmetry results from greater sensitivity of WPI to near-inertial wind forcing in the subtropical ocean relative to the subpolar ocean (cf. Section 4). During positive NAO phases, the storm track is shifted northward into the subpolar North Atlantic where enhanced storm activity is unable to generate enough extra WPI to make a noticeable difference to basin-wide WPI. During negative NAO phases, on the other hand, the storm track is shifted southward into the subtropics where storms are efficient at generating extra WPI that contributes significantly to the basin total. This asymmetry is partially reflected by the fact that subpolar WPI for any given year is up to one order of magnitude smaller than subtropical WPI (Fig. 10b, note that the two time series correspond to different $y$-axis).

In summary, our analysis showed that the relationship between NIWSM and WPI depends on latitude, with NIWSM being considerably more effective in generating WPI in lower latitudes. Because NIWSM is related to the storm track, WPI at low and high latitudes is found to be significantly correlated to the NAO: Enhanced WPI occurs in the subtropical (subpolar) North Atlantic during negative (positive) NAO conditions. The main variations are found in the eastern North Atlantic and are associated with the variability of the storm track tail. Basin-wide WPI is negatively correlated with the NAO and is found to be significantly enhanced under negative NAO conditions, but not significantly different from the climatological average under positive NAO conditions. Overall, the relationship between the NAO and basin-wide WPI is weaker and opposite of what one would have intuitively expected, i.e. that enhanced overall storm activity enhances basin-wide WPI.

\section{Discussion and conclusion}

In this study, we use a combination of atmospheric reanalysis data and a high-resolution ocean model to investigate for the first time the relationship between the interannual variability of WPI to near-inertial motions in the North Atlantic and the NAO by exploiting the relationship between WPI and NIWS M. Our approach is motivated by two observations: (1) storms are responsible for the majority of WPI and (2) the NAO 
serves as a good indicator for storm activity over the North Atlantic sector.

Consistent with previous studies, positive NAO years tend to produce more intense and more frequent storms and shift the storm track into the Nordic Seas, whereas in negative NAO years, the storm track is of reduced intensity and becomes more zonally oriented. These changes of storm activity have a direct influence on the distribution of near-inertial wind forcing. For example, the spatial pattern and magnitude of near-inertial wind stress closely resemble those of the storm track. There is, however, a southward displacement of near-inertial wind stress relative to the storm track of approximately $10^{\circ}$, which can be explained by latitudinal variations of the inertial frequency as well as the (red) nature of the wind stress spectra.

To investigate the impact of near-inertial wind stress changes associated with the NAO on WPI, we forced a high-resolution eddying ocean model of the North Atlantic with wind forcing from the winters of 1989 and 2010. These two winters are characterised by exceptionally high (1989) and low (2010) NAO indices. We found that the pattern of WPI closely resembles that of mean NIWSM and that WPI is moderately enhanced in the subpolar North Atlantic in 1989 but strongly enhanced in the subtropical North Atlantic in 2010. Integrated over the North Atlantic basin, WPI to near-inertial motions in 1989 is about $6.48 \mathrm{GW}$, much less than the $9.64 \mathrm{GW}$ produced in 2010 , even though there are more frequent and more intense storms in the winter of 1989. This paradox, we believe, can be explained largely by the variation of the Coriolis parameter with latitude, which leads to greater sensitivity of WPI to near-inertial wind forcing at lower latitudes by influencing both the magnitude and period of near-inertial motions. Other factors such as shallow mixed layer depths and higher cancellation ratios in the subtropics may also play a role. A detailed assessment of the relative roles played by these individual factors in enhancing subtropical WPI is not attempted and is left for a future study.

We show that mean NIWSM can serve as a useful proxy for WPI and develop linear regression models for WPI based on mean NIWSM in three latitude bands. The linear relationship between WPI and mean NIWSM strengthens towards the equator, again expressing greater sensitivity of WPI to nearinertial wind forcing at lower latitudes. We then use the linear regression models to investigate interannual variability of WPI in the North Atlantic for the period of 1980 to 2013 and its relationship to the NAO. WPI at low and high latitudes is found to be significantly correlated to the NAO, with higher WPI in the subtropical (subpolar) North Atlantic under negative (positive) NAO conditions owing to the relationship between the NAO and the storm track tail. Basin-wide WPI is found to be significantly enhanced under negative NAO conditions, but is not significantly different from the climatological average under positive NAO conditions. This asymmetry results, again, from greater sensitivity of WPI to near-inertial wind forcing in the subtropical ocean relative to the subpolar ocean. The overall relationship between the NAO and WPI is weakly negative, contrary to intuition.

In this study, we focused on WPI to near-inertial motions based on the argument that near-inertial energy contributes importantly to the diapycnal mixing both in the upper and deep ocean. We point out that WPI in general is not inherently confined to near-inertial motions but occurs over a wide range of frequencies, including slowly varying currents such as those established by the ocean general circulation (e.g. Oort et al. 1994; Wunsch 1998). However, considering the entire, continuous internal wave spectrum and its importance for diapycnal mixing, it has been recognised that the nearinertial band of internal waves stands out in several aspects (e.g. Garret 2001). Firstly, the generation of internal waves with frequencies close to the local inertial frequency is dominant, confining most of the energy of the internal wave field to this specific frequency band. Secondly, near-inertial waves exhibit propagation properties different from the rest of the internal wave field which allow them to penetrate the deep ocean under suitable conditions (see e.g. Anderson and Gill 1979; Kunze 1985; Lee and Niiler 1998 for a discussion of the propagation properties of near-inertial waves). Consequently, near-inertial waves are capable of propagating away from the area of their generation towards the deep ocean and the equator, feeding super-inertial internal waves into the internal wave field at lower latitudes.

However, dealing exclusively with near-inertial quantities introduces a considerable obstacle concerned with the employed wind (stress) product. NCEP/NCAR wind stress, the product used here, is only available every $6 \mathrm{~h}$, which is known to underestimate WPI to near-inertial motions (e.g. Jiang et al. 2005; Rimac et al. 2013). Furthermore, our ocean model is driven by wind stress computed with NCEP/NCAR $10 \mathrm{~m}$ wind alone, and as such, the ocean surface velocity in the model plays no role in the calculation of wind stress. A recent study by Rath et al. (2013) found a reduction of WPI by more than $20 \%$ in their eddying Southern Ocean model when the ocean surface velocity dependence is accounted for in the wind stress calculation. These problems highlight the need for developing high-resolution wind products and improving wind stress parameterisations in order to provide accurate estimates of WPI.

Another potential problem concerns the NAO itself. The NAO index during the study time period (1980-2013) is biased towards positive NAO conditions due to multi-decadal variability of the NAO, with a mean of 0.5 and composites for positive and negative conditions of 2.4 and -1.3 , respectively (cf. Fig. 1), suggesting that the magnitude of positive NAO events is stronger than that of negative NAO events. Biases towards the positive NAO phase are likely present in climatological quantities discussed here, as well as in composite quantities. Note, however, that the results of the linear regression models - on the basis of which interannual variability of 
WPI patterns was discussed - are not subject to the bias. Data for the models was taken from the years 1989 and 2010 exclusively. The NAO indices during these winters were 2.9 and -2.3 , respectively, i.e. they were comparable in magnitude.

In this study, we have focused our attention on interannual variability of wind power input to near-inertial motions at the sea surface. It would be interesting to see whether such variability has an impact on SST and how deep its influence on near-inertial energy can penetrate. We leave these topics to a future study.

Acknowledgments We thank Sergey Gulev and Natalia Tilinina of the P. P. Shirshov Institute of Oceanology of the Russian Academy of Sciences for kindly providing the storm path data. Numerical model experiments were carried out on the High Performance Computing Cluster supported by the Research and Specialist Computing Support service at the University of East Anglia. RJG and WR are grateful for the support from the GEOMAR. We would also like to thank two anonymous reviewers for their helpful comments.

\section{References}

Alford MH (2003) Improved global maps and 54-year history of windwork on ocean inertial motions. Geophys Res Lett 30:1424. doi:10. 1029/2002GL016614

Anderson DLT, Gill AE (1979) Beta dispersion of inertial waves. J Geophys Res 84:1836-1842. doi:10.1029/JC084iC04p01836

Blackmon ML, Wallace JM, Lee Y-H (1984a) Horizontal structure of $500-\mathrm{mb}$ height fluctuations with short, medium and long time scales. J Atmos Sci 41:784-812

Blackmon ML, Lee Y-H, Wallace JM, Hsu H-H (1984b) Time variation of $500 \mathrm{mb}$ height fluctuations with long, intermediate and short time scales as deduced from lag-correlation statistics. J Atmos Sci 41: 981-991

Chang S, Anthes R (1978) Numerical simulations of the ocean's nonlinear, baroclinic response to translating hurricanes. J Phys Oceanogr 8: 468-480

D'Asaro EA (1985) The energy flux from the wind to near-inertial motions in the surface mixed layer. J Phys Oceanogr 15:1043-1059

Furuichi N, Hibiya T, Niwa Y (2008) Model-predicted distribution of wind-induced internal wave energy in the world's oceans. J Geophys Res Oceans 113, C09034. doi:10.1029/2008JC004768

Garret C (2001) What is the "near-inertial" band and why is it different from the rest of the internal wave spectrum? J Phys Oceanogr 4: 962-971

Gill AE (1984) On the behaviour of internal waves in the wakes of storms. J Phys Oceanogr 14:1129-1150

Greatbatch RJ (1983) On the response of the ocean to a moving storm: the nonlinear dynamics. J Phys Oceanogr 13:357-637

Greatbatch RJ (2000) The North Atlantic Oscillation. Stoch Env Res Risk A 14:0213-0242

Guan S, Zhao W, Huthnance J, Tian J, Wang J (2014) Observed upper ocean response to typhoon Megi (2010) in the Northern South China Sea. J Geophys Res Oceans 119:3134-3157

Gulev SK, Zolina O, Grigoriev S (2001) Extratropical cyclone variability in the Northern Hemisphere winter from the NCEP/NCAR reanalysis data. Clim Dyn 17:795-809

Hurrell JW (1995) Decadal trends in the North Atlantic Oscillation: regional temperatures and precipitation. Science 269:676-679
Hurrell JW, Kushnir Y, Ottersen G, Visbeck M (2003) The North Atlantic Oscillation: climate significance and environmental impact. Geophys Monogr Ser 134. doi:10.1029/GM134

Jiang J, Lu Y, Perrie W (2005) Estimating the energy flux from the wind to ocean inertial motions: the sensitivity to surface wind fields. Geophys Res Lett 32, L15610. doi:10.1029/2005GL023289

Jochum M, Briegleb BP, Danabasoglu G, Large WG, Norton NJ, Jayne SR, Bryan FO (2013) The impact of oceanic near-inertial waves on climate. J Clim 26:2833-2844. doi:10.1175/JCLI-D-12-00181.1

Kalnay E et al (1996) The NCEP/NCAR 40-year reanalysis project. Bull Am Meteorol Soc 77:437-471

Kunze E (1985) Near-inertial wave propagation in geostrophic shear. J Phys Oceanogr 15:544-565

Large W, McWilliams J, Doney S (1994) Oceanic vertical mixing: A review and a model with a nonlocal boundary layer parameterization. Reviews of Geophysics 32:363-403

Lau N-C (1988) Variability of the observed midlatitude storm tracks in relation to low-frequency changes in the circulation pattern. J Atmos Sci 45:2718-2743

Lee D-K, Niiler PP (1998) The inertial chimney: the near-inertial energy drainage from the ocean surface to the deep layer. J Geophys Res 103:7579-7591

Marshall J, Adcroft A, Hill C, Perelman L, Heisey C (1997) A finitevolume, incompressible Navier Stokes model for studies of the ocean on parallel computers. J Geophys Res Oceans (1978-2012) 102:5753-5766

Munk W, Wunsch C (1998) Abyssal recipes II: energetics of tidal and wind mixing. Deep-Sea Res 45:1977-2010

Oort AH, Anderson LA, Peixoto JP (1994) Estimates of the energy cycle of the oceans. J Geophys Res Oceans 99:7665-7688

Plueddemann AJ, Farrar JT (2006) Observations and models of the energy flux from the wind to mixed-layer inertial currents. Deep-Sea Res 53:5-30

Pollard RT, Millard RCJ (1970) Comparison between observed and simulated wind-generated inertial oscillations. Deep-Sea Res 17:153-175

Price JF (1981) Upper ocean response to a hurricane. J Phys Oceanogr 11(2):153-175

Rath W (2013) The influence of ocean-surface-velocity-dependent wind stress on the dynamics of the Southern Ocean: the near-inertial and the sub-inertial response. PhD thesis, Christian-AlbrechtsUniversität Kiel, 113 pp

Rath W, Greatbatch RJ, Zhai X (2013) Reduction of near-inertial energy through the dependence of wind stress on the ocean-surface velocity. J Geophys Res Oceans 118:2761-2773. doi:10.1002/jgrc.20198

Rath W, Greatbatch RJ, Zhai X (2014) On the spatial and temporal distribution of near-inertial energy in the Southern Ocean. J Geophys Res Oceans 119:359-376. doi:10.1002/2013JC009246

Rimac A, von Storch JS, Eden C, Haak H (2013) The influence of highresolution wind stress field on the power input to near-inertial motions in the ocean. Geophys Res Lett 40:4882-4886. doi:10.1002/grl.50929

Rogers JC (1997) North Atlantic storm track variability and its association to the North Atlantic Oscillation and climate variability of northern Europe. J Clim 10:1635-1647

Thomson RE (1983) A comparison between computed and measured oceanic winds near the British Columbia coast. J Geophys Res Oceans 88:2675-2683

Von Storch H, Zwiers FW (1999) Statistical analysis in climate research. Cambridge University Press, Cambridge, $495 \mathrm{pp}$

Wallace JM, Gutzler DS (1981) Teleconnections in the geopotential height field during the Northern Hemisphere winter. Mon Weather Rev 109:784-812

Wallace JM, Lim G-H, Blackmon ML (1988) Relationship between cyclone tracks, anticyclone tracks and baroclinic waveguides. J Atmos Sci 45:439-462

Watanabe M, Hibiya T (2002) Global estimates of the wind-induced energy flux to inertial motions in the surface mixed layer. Geophys Res Lett 29:2-5 
Wunsch C (1998) The work done by the wind on the oceanic general circulation. J Phys Oceanogr 28:2332-2340

Zhai X, Marshall DP (2013) Vertical eddy energy fluxes in the North Atlantic subtropical and subpolar gyres. J Phys Oceanogr 43:95-103

Zhai X, Greatbatch RJ, Zhao J (2005) Enhanced vertical propagation of storm-induced near-inertial energy in an eddying ocean channel model. Geophys Res Lett 32, L18602. doi:10.1029/2005GL023643

Zhai X, Greatbatch RJ, Eden C (2007) Spreading of near-inertial energy in a $1 / 12^{\circ}$ model of the North Atlantic Ocean. Geophys Res Lett 34, L10609. doi:10.1029/2007GL029895

Zhai X, Greatbatch RJ, Eden C, Hibiya T (2009) On the loss of windinduced near-inertial energy to turbulent mixing in the upper ocean. J Phys Oceanogr 39:3040-3045 